\title{
MiRNA-124 regulates the sensitivity of renal cancer cells to cisplatin-induced necroptosis by targeting the CAPN4-CNOT3 axis
}

\author{
Qingyan Mao, Qianfeng Zhuang, Jie Shen, Zhen Chen, Dong Xue, Tao Ding, Xiaozhou He \\ Department of Urology, The Third Affiliated Hospital of Soochow University, Changzhou, China \\ Contributions: (I) Conception and design: X He, Q Mao; (II) Administrative support: X He, D Xue; (III) Provision of study materials or patients: Q \\ Mao, Q Zhuang, T Ding; (IV) Collection and assembly of data: Q Mao, J Shen, Z Chen; (V) Data analysis and interpretation: Q Mao, J Shen, Z \\ Chen; (VI) Manuscript writing: All authors; (VII) Final approval of manuscript: All authors. \\ Correspondence to: Xiaozhou He. Department of Urology, The Third Affiliated Hospital of Soochow University, 185 Juqian Street, Changzhou \\ 213003, China.xiaozhouhe123@163.com.
}

Background: Currently, drug-resistance is a major challenge in the treatment of renal cancer. Although microRNAs (miRNAs) have been reported to contribute to the incidence of drug resistance in renal cancer, the bio-functional roles and underlying regulatory mechanisms of novel miRNAs in cisplatin resistance remain largely unclear.

Methods: In this study, miRNA microarray analysis was applied to evaluate miRNA changes induced by cisplatin on RCC (renal cell carcinoma) cell lines. Then, Caki-1 and 786-0 cells were transfected with miR (miRNA)-124 mimics to observe cisplatin resistance in RCC cell lines after up-regulation of miR124. TargetScan was used to identify putative protein-coding gene targets of miR-124. Further, the interaction between calpain small subunit 1 (Capn4) and CCR4-NOT transcription complex subunit 3 (CNOT3) was detected by quantitative real-time PCR (qPCR) and western blotting, and confirmed by coimmunoprecipitation. The effect of Capn4 and/or CNOT3 on cell viability and half maximal inhibitory concentration (IC50) value of miR-124 overexpressed Caki-1 and 786-O cells to cisplatin was evaluated using the Cell Counting Kit-8 (CCK-8) assay. And the effect of Capn4 and/or CNOT3 on the level of necroptosis in miR-124 overexpressed Caki-1 and 786-O cells to cisplatin was evaluated by flow cytometric analysis. Then, four groups of 786-0 cells (miR-124, miR-124+ Capn4, miR-124+ CNOT3, miR-124+ Capn4+ CNOT3) were inoculated into nude mice to observe the effect of cisplatin on tumor formation.

Results: miR-124 was found to be markedly elevated in renal cancer cells by cisplatin. Functionally, the overexpression of miR-124 reduced the sensitivity of renal cancer cells to cisplatin and CAPN4 was found to be a direct target of miR-124, which can negatively regulated CAPN4 expression. Moreover, ectopic expression of CAPN4 reversed the impairment of miR-124 on cisplatin-sensitivity and cisplatin-induced necroptosis. Mechanically, the present study revealed that CAPN4 could directly interact with CNOT3 and promote its degradation, and that the cisplatin-resistant phenotype was reversed by up-regulation of CNOT3.

Conclusions: Therefore, miR-124 is an important inhibitor in cisplatin-induced necroptosis, and the miR124-CAPN4-CNOT3 signaling axis plays a critical role in the emergence of cisplatin-resistance.

Keywords: Renal cell carcinoma (RCC); cisplatin-resistance; miRNA-124; calpain small subunit 1 (Capn4); CCR4-NOT transcription complex subunit 3 (CNOT3)

Submitted Jul 23, 2021. Accepted for publication Sep 18, 2021.

doi: $10.21037 /$ tau-21-777

View this article at: https://dx.doi.org/10.21037/tau-21-777 


\section{Introduction}

Renal cell carcinoma (RCC) is a common neoplasm in the urinary system, which ranks second in urinary tumor mortality, accounting for nearly $4 \%$ of all adult malignancies (1-3). Owing to its simplicity and rapid effect, chemotherapy is recognized as the most ideal treatment method (3-6). However, tumor insensitivity to chemotherapy and the gradual development of drug resistance has presented difficulties, which is a significant challenge for RCC treatment. Therefore, exploring the underlying mechanisms of drug resistance is critical to the development of effective treatment strategies.

MicroRNAs (miRNAs) are a kind of small noncoding RNA of 18-25 nt in length that can induce posttranscriptional inhibition by binding directly to the mRNA (messenger RNA) 3'-untranslational region (UTR) $(7,8)$. It has been well documented that miRNAs play an important role in various important biological processes, including cell growth, differentiation, proliferation, and programmed cell death (9-11). In addition, numerous miRNAs are involved in RCC, including down-regulated miRNAs [miR-141 (12), miR-200c (13), miR-23b (14), miR-27b (15), and miR-135a (16)] and up-regulated miRNAs [miR-221 (17)], which have been found in RCC cells or tissues.

However, RCC resistance is not fully understood in terms of the underlying mechanisms of miRNAs regulation. MiR-124 has been reported to play an important role in the anticancer mechanism of various cancers, including glioma, ovarian cancer, gastric cancer, non-small cell lung cancer, and liver cancer (18-22). It is also thought to play an oncogenic role in $\operatorname{RCC}(23,24)$. Furthermore, miR124 contributes to glioma drug-resistance by targeting R-RAS and N-RAS (25); however, its role and mechanism of action in the development of drug resistance in human RCC remains unclear. Recently, studies on therapy of RCC mainly focused on targeted therapy and immunotherapy, but rarely on chemotherapy. This study was the first to investigate the potential mechanism of miR-124 in cisplatin-resistance in RCC.

In this study, we demonstrated that miR-124 is an essential inhibitor in cisplatin-induced necroptosis, and the miR-124-CAPN4-CNOT3 signaling axis plays a key role in inducing cisplatin-resistance. Therefore, our data elucidates the novel role of miR-124 in inducing drug resistance in RCC and provides an effective therapeutic strategy for the treatment of RCC. We present the following article in accordance with the ARRIVE reporting checklist (available at https://dx.doi.org/10.21037/tau-21-777).

\section{Methods}

\section{Cells and reagents}

Human RCC cell lines, 786-O and Caki-1, were purchased from the ATCC (American Type Culture Collection) and cultured in RPMI (Roswell Park Memorial Institute) 1640 for 786-O or McCoy's 5a for Caki-1 (ThermoFisher, USA), supplemented with $10 \%$ FBS (Fetal Bovine Serum, ThermoFisher, USA) and $2 \mathrm{mM} \mathrm{L}$-glutamine (ThermoFisher, USA). Cisplatin was obtained from Selleck (Shanghai, China).

\section{MiRNA microarray}

A total RNA isolation kit of mirVana miRNA (Ambion, USA) was used to extract total RNA from cultured cells. cRNA (complementary RNA) per sample was synthesized and labeled in the buffer. The labeled cRNA fragments were used in the MicroRNA2.0 array (Affymetrix, USA) and hybridized in a GeneChip hybrid oven 640 (Affymetrix, USA) After cleaning and staining, the array was scanned using GeneChip Scanner 3000 (Affymetrix, USA). Partek GS 6.5 (Partek Inc., USA) was used to normalize and compare the miRNA expression levels of the samples. Average link hierarchy clustering was used for the data and Treeview was used to display the clustering results (http://rana.lbl.gov).

\section{Cell proliferation and drug half maximal inbibitory concentration (IC50) determination}

A CCK -8 (Cell Counting Kit-8) assay was used to evaluate cell proliferation. Briefly, RCC cells were seeded in 96well plates $\left(10^{3}\right.$ cells/well) and cultured for $24 \mathrm{~h}$ (denoted as day 0 ). The cells were then treated as indicated with four replications. At the specified time point, a $10 \mathrm{~mL}$ CCK- 8 reagent solution (Donjido, Japan) was added to each well and incubated for $1 \mathrm{~h}$. The optical density and absorbance at $450 \mathrm{~nm}$ were determined by a microplate reader (Bio-Tek, USA). The CCK-8 experiment was repeated at least three times. The data were used to generate drug effects or cell proliferation rate curves.

\section{$R N A$ isolation and $q P C R$}

Total RNA from tissue and cell lines was extracted using 
Table 1 The primers for $\mathrm{qPCR}$

\begin{tabular}{lll}
\hline Primer name & Forward & Reverse \\
\hline MiR-124 & 5'-ACACTCCAGCTGGGTAAGGCACGCGGTGA-3' & 5'-TGGTGTCGTGGAGTCG-3' \\
U6 & 5'GCTTCGGCAGCACATATACTAAAAT3' & 5'CGCTTCACGAATTTGCGTGTCAT3' \\
CAPN4 & 5'-TCCGACGCTACTCAGATGAAAGT-3' & 5'-GATTTGTCCAGTGCCATCTTTGT-3' \\
CNOT3 & 5'-AAGAAGAAAGGCGACAAGGA-3' & 5'-GTCCAGCATTCGCAGGAT-3' \\
GAPDH & 5'-TGACTTCAACAGCGACACCCA-3' & 5'-CACCCTGTTGCTGTAGCCAAA-3' \\
\hline
\end{tabular}

TriZol (Thermo Fisher, USA). The quantification of miRNA levels was evaluated using a miRNA quantitative real-time PCR (qPCR) assay kit (GeneCopoeia, USA). To quantify mRNA levels of CAPN4 and CNOT3, a reverse transcription (RT) reaction was performed using a RevertAid ${ }^{\mathrm{TM}} \mathrm{H}$ Minus First Strand cDNA Synthesis Kit (Fermentas, Canada) and performed using the ABI 7900 system (ABI, USA). U6 and GAPDH were used as normal controls for miRNA and mRNA quantification, respectively. The $2^{-\Delta \Delta \mathrm{Ct}}$ method to calculate the relative expression levels. The primers were shown in Table 1 .

\section{MiRNA transfection}

Both the negative control (NC) and miR-124 mimics (mimics) were purchased from GenePharma (Shanghai, China). Lipofectamine 2000 transfection reagent (Invitrogen, USA) was used to transfect cells with NC and simulators according to the manufacturer's protocol. Transfection efficiency was detected by qRT-PCR.

\section{Western blotting}

Total cell protein was extracted using RIPA (RadioImmunoprecipitation Assay) buffer solution containing protease inhibitor PMSF (Phenylmethanesulfonyl fluoride), phosphatase inhibitor $\mathrm{NaF}$ (sodium fluoride), and $\mathrm{Na}_{3} \mathrm{VO}_{4}$ (sodium orthovanadate) (Roche, Switzerland). Western blotting detection was applied as described previously (26). The level of each protein film band was quantified by Quantity One (Bio-Rad, USA). The primary antibodies [CAPN4 $(1: 1,000)$ and CNOT3 $(1: 2,000)]$ were purchased from Abcam (UK). All protein expression experiments were repeated at least three times.

\section{Luciferase reporter gene assays}

The 3'-UTR of CAPN4 (miR-124 binding site) was synthesized and subcloned into a pGL3 reporter plasmid (Promega, USA). The plasmid was co-transfected with miR-124 mimics or miR-NC into 786-O cells for $48 \mathrm{~h}$. 786-O cells were collected and the activity of luciferase was measured using the dual-luciferase reporter assay kit (Promega, USA).

\section{Apoptosis and necroptosis assay}

Annexin V/FITC (fluorescein isothiocyanate) Detection Kit (ThermoFisher, USA) was used to detect apoptosis and necroptosis. After transfection, the cells were incubated for $24 \mathrm{~h}$, collected, and washed with phosphate-buffered saline (PBS) twice. FITC-Annexin V (5 mL) and PI (propidium iodide) $(10 \mathrm{~mL})$ were added and incubated for $15 \mathrm{~min}$ at $25{ }^{\circ} \mathrm{C}$. The stained cells were counted by flow cytometry and FACScalibur (BD, USA) was used to analyze apoptosis (AnnexinV+/PI-) and necroptosis (AnnexinV-/PI+). The experiment was repeated three times.

\section{Calpain activity}

As mentioned earlier, calprotease activity was determined by using the fluorescent substrate N-succinyl-LLVD-AMC and casein enzyme spectrum.

\section{Co-immunoprecipitation}

RCC cells were collected $48 \mathrm{~h}$ after transfection, washed with PBS, and then scraped into the lysis buffer. After freezing, the cells were centrifuged for clarification. Total lysate $(500-800 \mathrm{~mol} / \mathrm{L})$ was added based on protein G-sepharose (Amersham Pharmacia, Piscataway, NJ) at $10 \mathrm{~mol} / \mathrm{L}$ and anti-mouse immunoglobulin $\mathrm{G}$ (IgG) or anti-CapN4/CNOT3 antibody at $5 \mathrm{~mol} / \mathrm{L}$. After tilting incubation at $4{ }^{\circ} \mathrm{C}$ for $4 \mathrm{~h}$, the samples were repeatedly washed three times with $1 \%$ Nonidet P (NP)-40 buffer solution and then extracted with SDS (sodium dodecyl 
sulfate) sample buffer solution. The extract was analyzed on SDS-PAGE (polyacrylamide gel electrophoresis) with a gradient of 4-20\% and transferred to cellulose nitrate for western blot analysis.

\section{Xenograft model}

The 786-O cells $\left(1 \times 10^{6}\right.$ cells suspended in PBS containing $50 \%$ matrix gel) were stably transfected with LV(lentiviral vector)-miR-124, LV-CAPN4, or LV-CNTO3 (purchased from Genelily Biotechnology Company, Shanghai) and subcutaneously injected into the lateral ventral of BALB/C nude mice ( 6 weeks old, $\mathrm{n}=5$ in each group). Cisplatin was intraperitoneally administered once every 3 days. Tumor volume was recorded at 5-30 days after transplantation according to the following formula Tumor volume $=$ length $x$ width $2 / 2$. Tumor weight of transplanted mice was recorded 30 days after injection. This study was approved by the Ethics Committee of the Third Affiliated Hospital of Soochow University. The operation process of all experimental animals was strictly in accordance with the "Guide to the Care and Use of Experimental Animals" [2016].

\section{Statistical analyses}

SPSS 21.0 (IBM, Armonk, NY, USA) was used for statistical analysis. All statistical tests were bilateral. One-way analysis of variance (ANOVA) was used for comparison between groups. $\mathrm{P}<0.05$ was considered statistically significant.

\section{Results}

\section{MiR-124 contributed to cisplatin resistance in RCC cells}

To explore the miRNA expression altered by chemotherapy drugs, the RCC cell line, 786-O, was treated with cisplatin (as shown in Figure 1A). Next, miRNA microarray analysis was performed. A significant increase in miR124 was observed in cisplatin-induced changes in miRNAs (Figure $1 A$ ), which was confirmed by qPCR analysis (Figure 1B). To determine whether the increase in miR-124 was dependent on cisplatin concentration, we treated 786-O cells with different doses of cisplatin for $24 \mathrm{~h}$ and found that the expression level of miR-124 increased with the increase of cisplatin dose (Figure 1B).

To evaluate the biological effect of miR-124 on IC50 value, we cultured regular Caki-1 and 786-O cells in vitro, transfected with miR-124 mimic or scramble, and treated them with several doses of cisplatin (as indicated in Figure $1 C, 1 D$ ) after $24 \mathrm{~h}$ of miRNA transfection. The expression of miR-124 was dramatically increased after miR-124 mimic transfection in Caki-1 and 786-O cells. The curves showed that the IC50 value of cisplatin in Caki-1 cells was $0.93 \pm 0.12 \mu \mathrm{M}$, which increased to $4.89 \pm 0.63 \mu \mathrm{M}$ in the miR-124 mimic-transfected cells. A similar result was observed in 786-O cells. The IC50 value of cisplatin was $0.96 \pm 0.15 \mu \mathrm{M}$, which increased to $2.27 \pm 0.32 \mu \mathrm{M}$ after miR124 mimic transfection. These results suggested that miR124 is contributed to cisplatin resistance in RCC cells.

\section{MiR-124 post-transcriptionally inbibits CAPN4 expression by directly targeting its $3^{\prime}-U T R$}

We used the TargetScan bioinformatics analysis program (http://www.targetscan.org) to identify the recognized miR124 protein-coding gene targets. TargetScan miRNA target prediction revealed sthat the 3'-UTR of CAPN4 mRNA contains a potential binding site for miR-124 at nucleotide 427 (Figure 2A). To determine whether exogenous miR124 inhibits CANP4 expression, early miR-124 or control miRNA (miRNA-NC) was transfected into Caki-1 and 786$\mathrm{O}$ cells for $24 \mathrm{~h}$. The expression of CAPN4 was analyzed by RT-PCR (Figure 2B) and western blotting (Figure 2C). The ectopic expression of miR-124 significantly inhibited the expression of CAPN4 mRNA (Figure $2 B$ ) and protein (Figure 2C).

Next, we analyzed whether the 3'-UTR of CAPN4 mRNA is a critical target of miR-124 in RCC. The predicted CAPN4 miRNA binding sequences [including wildtype (wt) and mutant (Mut) sequences] were cloned into a downstream region constructed by a luciferase reporter gene (psiCheck-CAPN4 3 'UT-wt/Mut, Figure 2D). These constructs were transiently transfected into 786-O cells in the presence of miR-124 mimic or miRNA-NC. As shown in Figure 2E, compared with miRNA-NC, miR-124 significantly decreased the luciferase activity of pSiCheckCAPN4 3'UTR, but miR-124 could not reduce the luciferase activity of pSiCheck-CAPN4 3'UTR-Mut. These results indicate that miR-124 specifically binds CAPN4's 3-UTR nucleotide 427 and reduces the expression of CAPN4.

\section{Overexpression of CAPN4 abolishes the miR-124-induced decrease in cisplatin sensitivity}

Since miR-124 can inhibit the expression of CAPN4 through direct inhibition of CAPN4 transcripts, we 

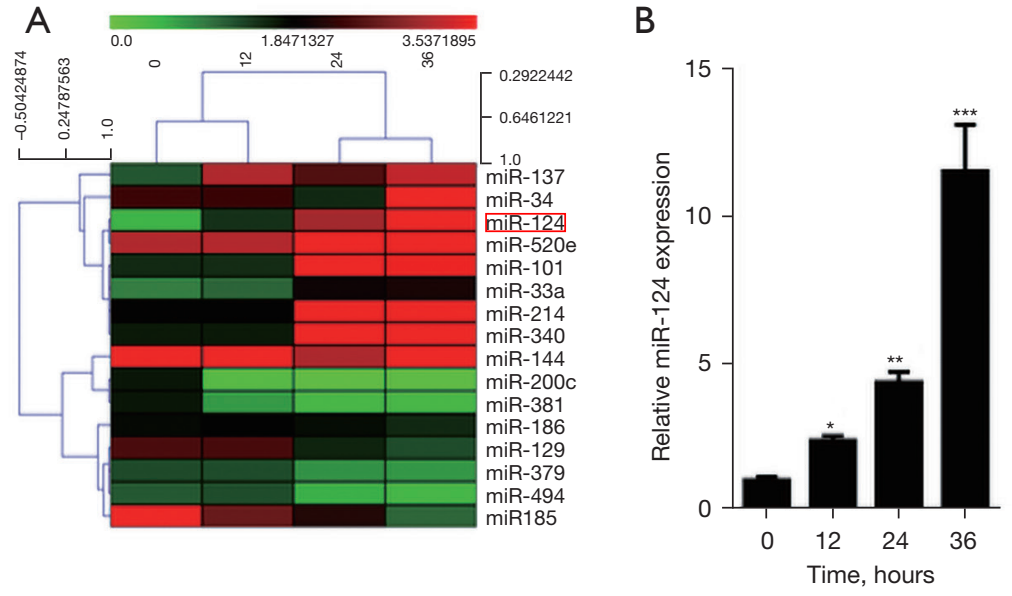

C $\begin{aligned} & \text { miR-NC } \\ & \text { miR-124 }\end{aligned}$
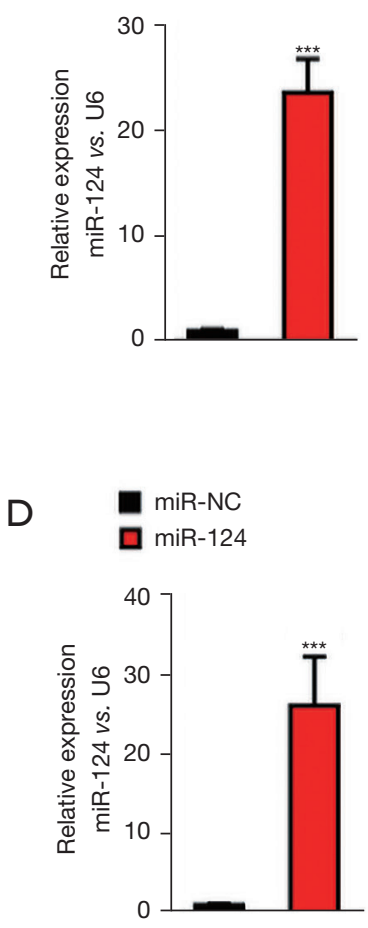

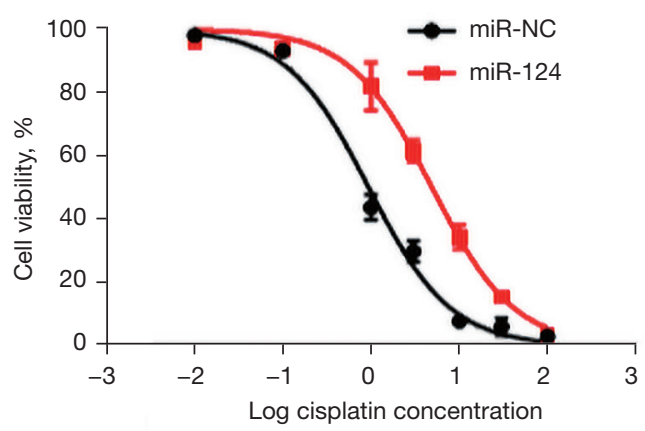

Caki-1

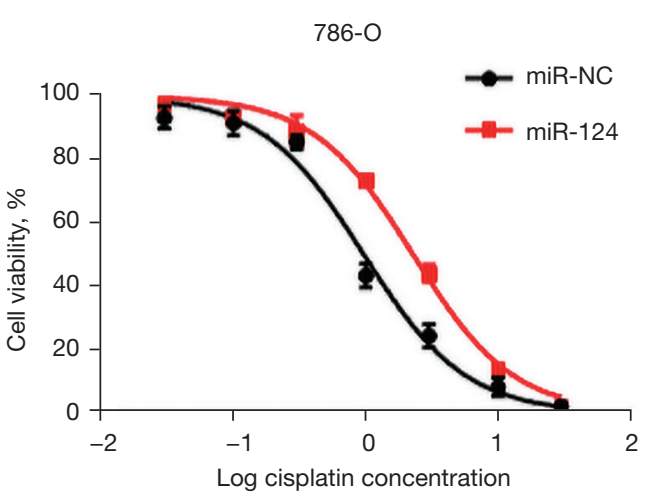

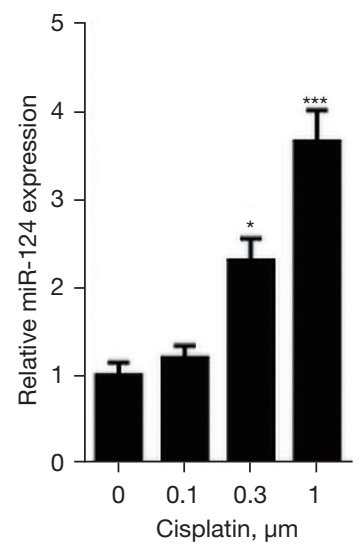

miR-NC

miR-124

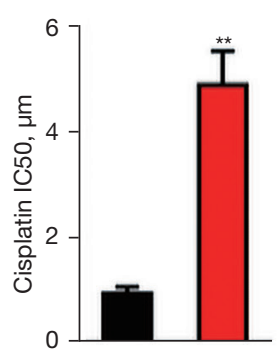

miR-NC

miR-124

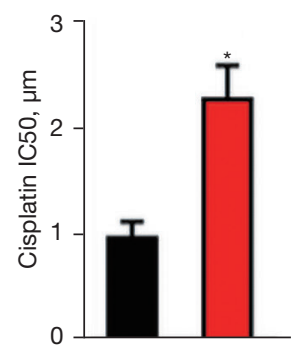

Figure $1 \mathrm{MiR}-124$ contributed to cisplatin resistance in renal cell carcinoma (RCC) cells. (A) 786-O cells were treated with $10 \mu M$ cisplatin for $0,12,24$, and $36 \mathrm{~h}$. The filtered miRNA array data were used for hierarchical clustering analysis. (B) The level of miR-124 was detected by real-time polymerase chain reaction (PCR). (C) The overexpression level of miR-124 in Caki-1 cells was measured by quantitative realtime PCR (qPCR). Cell viability and half maximal inhibitory concentration (IC50) value of Caki-1 cells to cisplatin were evaluated using the Cell Counting Kit-8 (CCK-8) assay. (D) The overexpression level of miR-124 in 786-O cells was measured by qPCR. Cell viability and IC50 value of 786-O cells to cisplatin were evaluated using the CCK-8 assay. *, $\mathrm{P}<0.05$; ${ }^{* *}, \mathrm{P}<0.01$; and ${ }^{* * *}, \mathrm{P}<0.001$. 
A

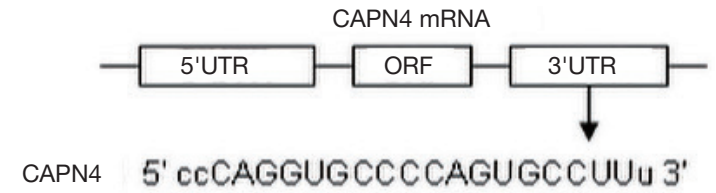

B
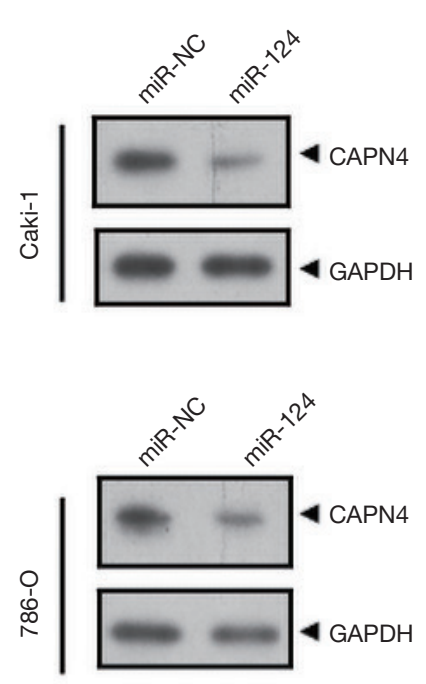
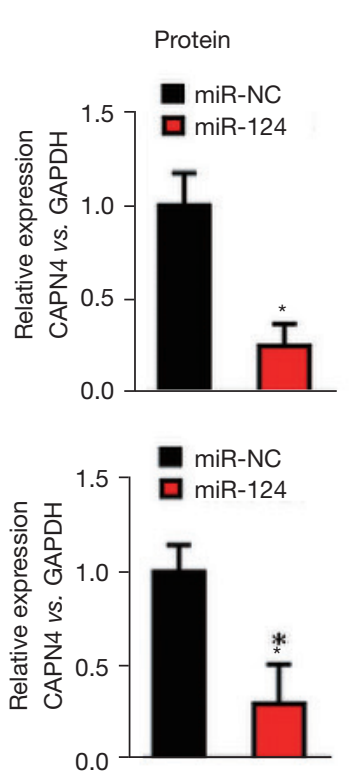

C

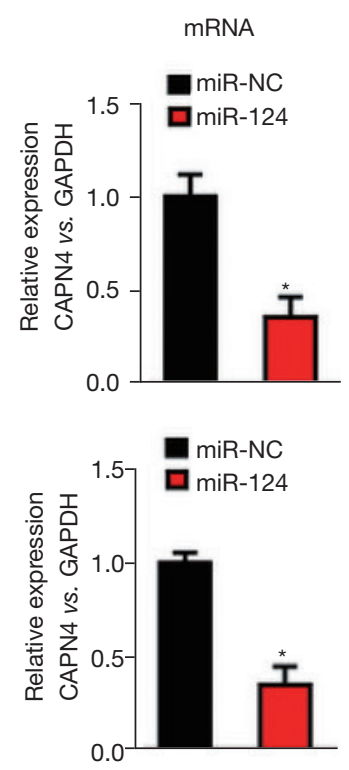

$E$

3'UTR-WT

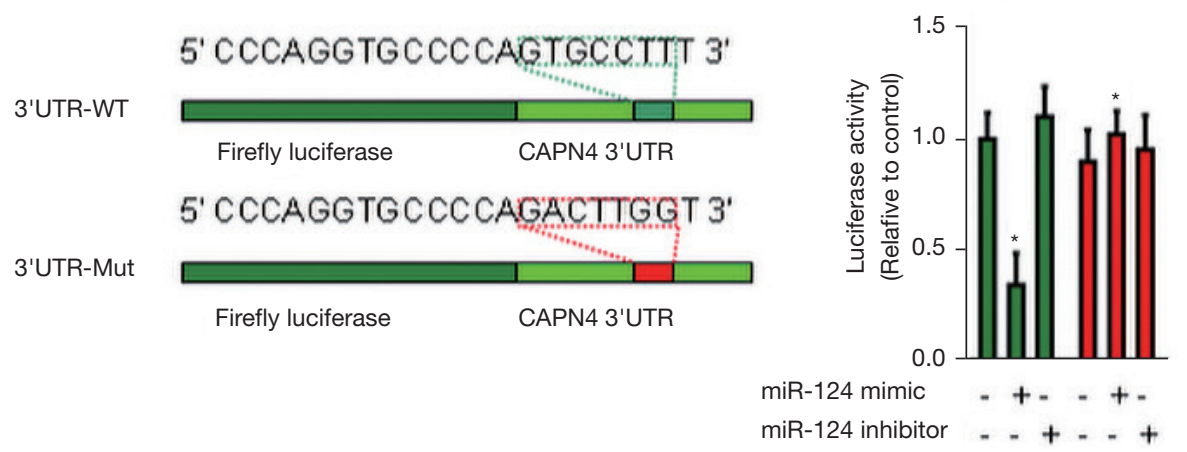

Figure 2 MiR-124 post-transcriptionally inhibits calpain small subunit 1 (CAPN4) expression by directly targeting its 3'-UTR. (A) Alignment of the miR-124 sequence with that of the 3'-UTR of CAPN4. (B)Western blot analysis revealed that the protein level of CAPN4 was decreased in the miR-124-overexpressed Caki-1 and 780-O cells. (C) The mRNA level of CAPN4 in the miR-124-overexpressed Caki-1 and 780-O cells was analyzed by real-time polymerase chain reaction (PCR) analysis. (D) CAPN4 3'-UTR constructs mutants at the predicted miR-124 site. (E) Dual-luciferase reporter activities of the pSiCheck2 vectors carrying the luciferase gene and a fragment of the CAPN4 3'-UTR containing the miR-124 binding sites in the control, miR-124 mimic, and miR-124 inhibitor groups. *, $\mathrm{P}<0.05$.

investigated whether increasing the expression of CAPN4 can reduce cisplatin resistance promoted by miR-124. Therefore, miR-124 was expressed in vitro in Caki-1 and
786-O cells and in CAPN4 encoding sequence, but was lacking a 3'-UTR or empty vector. CAPN4 overexpression was confirmed by western blotting (Figure $3 A$ ) and RT- 
PCR (Figure 3B). The curves indicated IC50 values of cisplatin in Caki-1 or 786-O cells (Figure 3C) showed that overexpression of CAPN4 completely abolishes the effect of miR-124 on the decreased cisplatin sensitivity. These results suggested that miR-124 reduced cisplatin sensitivity in RCC by targeting and inhibiting the expression of CAPN4.

\section{MiR-124 decreases the cisplatin-induced necroptosis but not apoptosis by repressing CAPN4}

To analyze the effect of miR-124 and CAPN4 on apoptosis and necrosis, Caki-1 and 786-O cells were randomly divided into four groups: miR-NC+vector control group, miR-124+vector control group, miR-NC+CAPN4 group, and miR-124+CPAN4 group. The cells were stimulated by cisplatin for $24 \mathrm{~h}$, and apoptosis and necrosis were detected by flow cytometry after Annexin V and PI staining. The two-dimensional quadrants of apoptosis and necrosis are shown in Figure $4 A, 4 B$. The results showed that miR-124 significantly reduced cell necrosis in Caki-1 (Figure $4 A$ ) and 786-O (Figure $4 B$ ) cells, while inhibition of CAPN4 reversed the cell necrosis induced by miR-124. The apoptotic level changed with the overexpression of miR-124 or CANP4. These results suggested that miR-124 reduces the sensitivity of cisplatin in RCC by inhibiting cisplatininduced renal cell necrosis rather than apoptosis.

\section{CAPN4 directly interacts with CNOT3 and promotes its degradation}

Considering CAPN4 is a subunit of calpain and decreasing CAPN4 abolishes the activity of calpain (27), we hypothesized that the calpain activity and its degraded protein are critical to the miR-124-induced decrease in cisplatin sensitivity in RCC. The results showed that miR124 markedly decreased the activity of calpain in Caki-1 and 786-O cells, which was significantly reversed after CAPN4 overexpression (Figure 5 A).

As the previous results suggested that $\mathrm{CNOT} 3$ could be degraded due to calpain activation (28), we directly examined whether or not CNOT3 was a substrate of calpain in RCC. As shown in Figure 5B, miR-124 significantly increased the protein level of CNOT3 and this increase was completely abolished by CAPN4 overexpression. However, the mRNA level of CNOT3 was unchanged by miR-124 or CAPN4 overexpression (Figure 5C). These results suggest that miR-124/CAPN4 may affect the level of CNOT3 by increasing its degradation, but not inhibition of its expression.
We then analyzed the direct interaction between CANP4 and CNOT4 by co-immunoprecipitation. The result showed that both CANP4 and CNOT4 directly interacted with each other (Figure 5D). From what has been discussed above, these results reveal that CAPN4 could interact with CNOT3 and promote its degradation.

\section{MiR-124 decreases the cisplatin sensitivity and cisplatin- induced necroptosis by inbibiting CAPN4-mediated CNOT3 degradation}

To evaluate the specific role of CAPN4-mediated CNOT3 degradation in the miR-124-induced decrease in cisplatin sensitivity and cisplatin-induced necroptosis, Caki1 and 786-O cells were divided into four groups: miR124, miR-124+CAPN4, miR-124+CNOT3, and miR$124+$ CPAN4+CNOT3. The efficiency of CAPN4 and CNOT3 overexpression was confirmed by western blot and qPCR (Figure 6A). The cells were then stimulated by cisplatin for 1 day. After staining with Annexin V and PI, apoptosis and necroptosis were detected by flow cytometry. The results showed that CAPN4 significantly decreased the IC50 of cisplatin in miR-124-overexpressed Caki-1 and 786-O cells, and this decreasing was completely abolished by CNOT3 overexpression (Figure $6 B$ ).

Similarly, CAPN4 markedly increased the level of necroptosis in miR-124-overexpressed Caki-1 and 786O cells, which was completely abolished by CNOT3 overexpression (Figure 6C). However, CNOT3 alone showed no effect on the IC50 of cisplatin (Figure 6B) and the level of necroptosis (Figure 6C) in miR-124overexpressed Caki-1 and 786-O cells. Nevertheless, the level of apoptosis was not changed with CAPN4 or CNOT3 overexpression (Figure 6C). In summary, these results reveal that miR-124 decreases the cisplatin sensitivity and cisplatin-induced necroptosis via inhibiting CAPN4mediated CNOT3 degradation.

\section{Effect of miR-124-CANP4-CNOT3 on cisplatin-resistance of 786-O cells in vivo}

To assess the effects of miR-124-CANP4-CNOT3 on cisplatin resistance of 786-O cells in vivo, we generated xenograft mice with four groups of Caki-1 cells (miR124, miR-124+CAPN4, miR-124+CNOT3, and miR124+CPAN4+CNOT3). Consistently, tumors derived from miR-124+CAPN4-transfected Caki-1 cells grew more slowly than those derived from only miR-124-transfected 

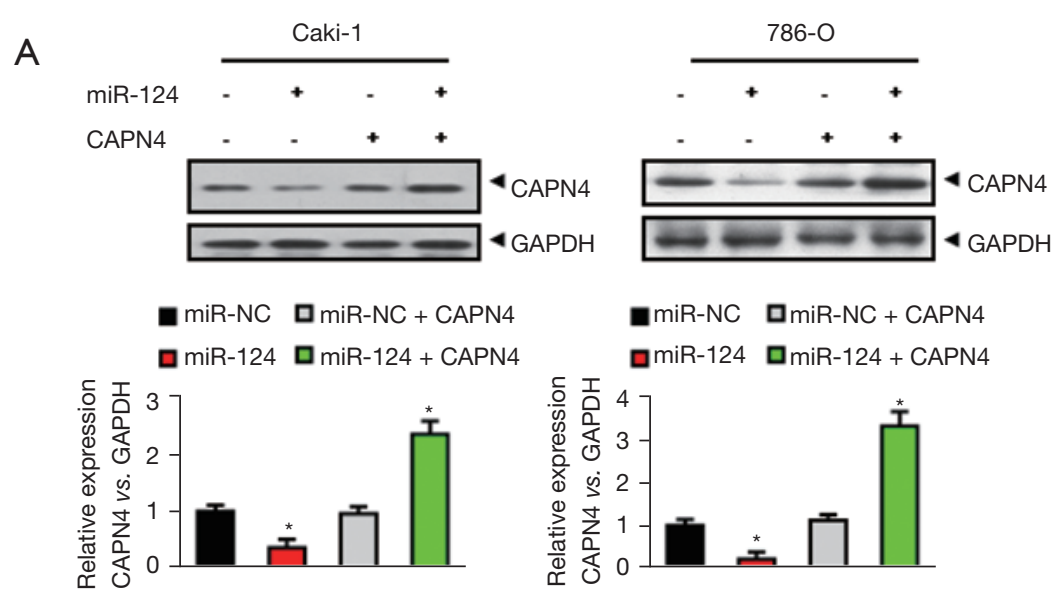

B
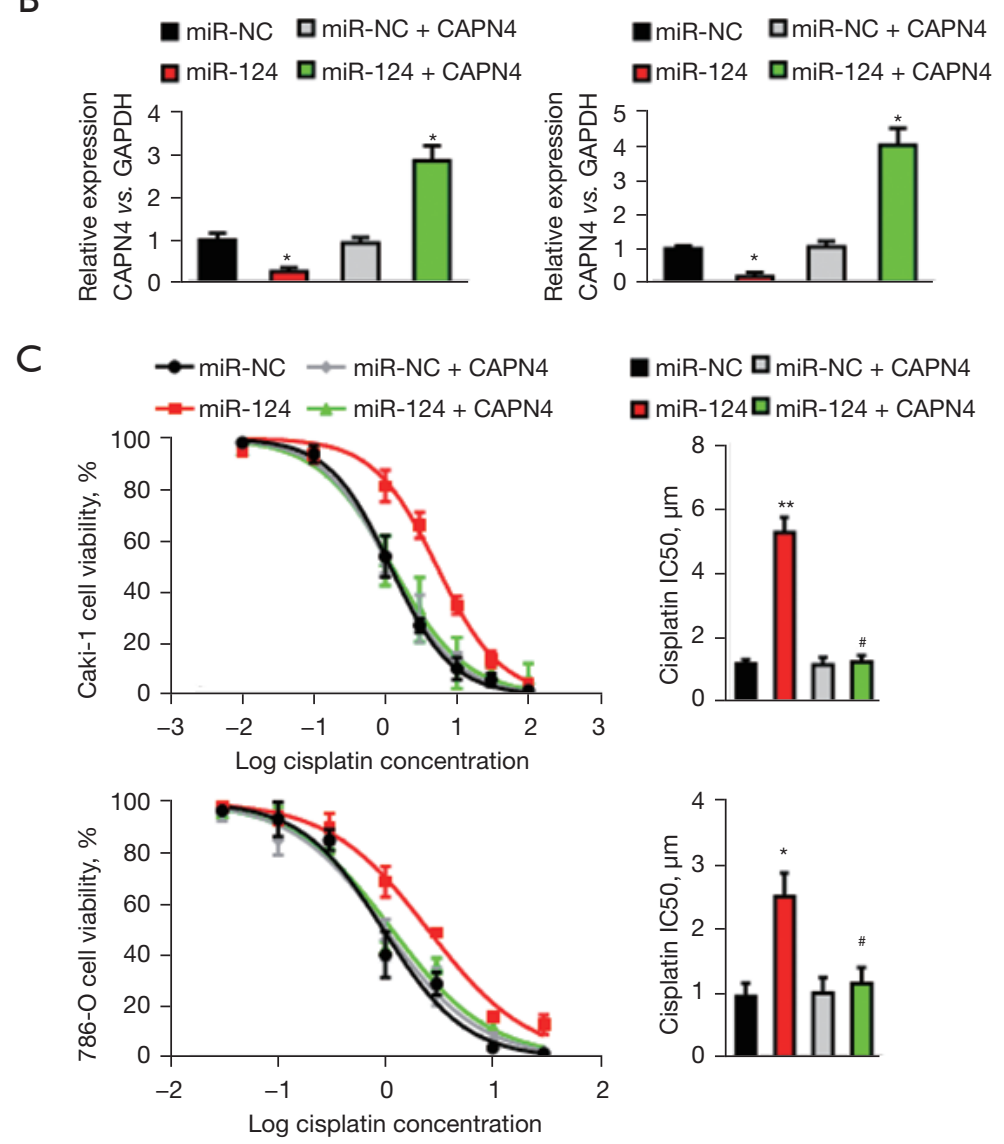

Figure 3 Overexpression of calpain small subunit 1 (CAPN4) abolishes the miR-124-induced decrease in cisplatin sensitivity. (A) The protein levels of CAPN4 in Caki-1 and 786-O cells was analyzed by western blot analysis. (B) The mRNA levels of CAPN4 in Caki-1 and 786-O cells was analyzed by real-time polymerase chain reaction (PCR) analysis. (C) The effect of miR-124 and/or CAPN4 on cell viability and the half maximal inhibitory concentration (IC50) value of Caki-1 and 786-O cells to cisplatin was evaluated using the Cell Counting Kit-8 (CCK-8) assay. * $\mathrm{P}<0.05$; **, $\mathrm{P}<0.01$ vs. miR-NC group; ${ }^{*}, \mathrm{P}<0.05$ vs. miR-124 group. 
A
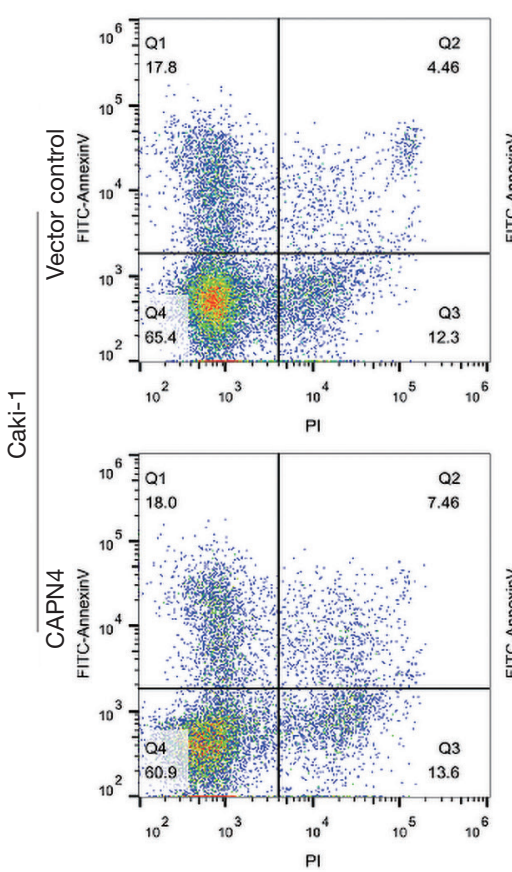

B

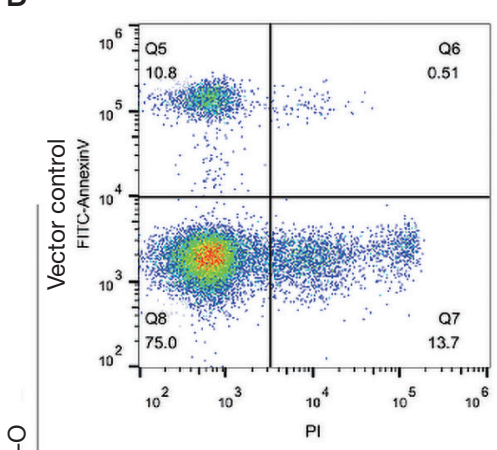

0
1
1
1

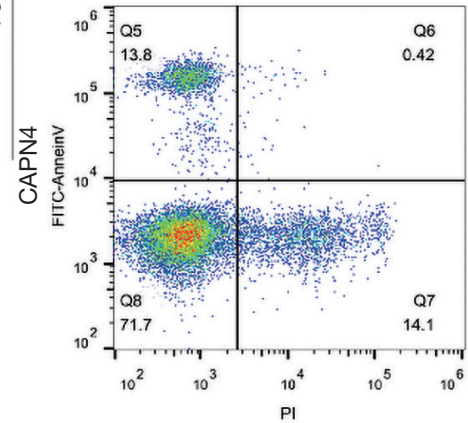

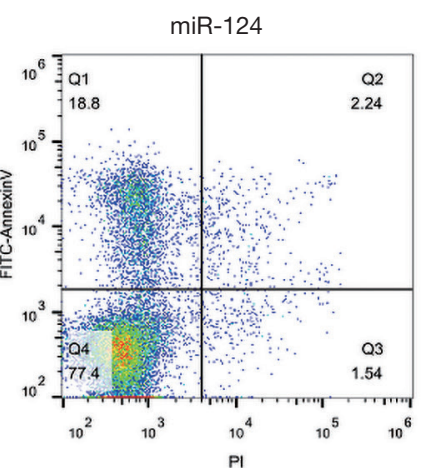

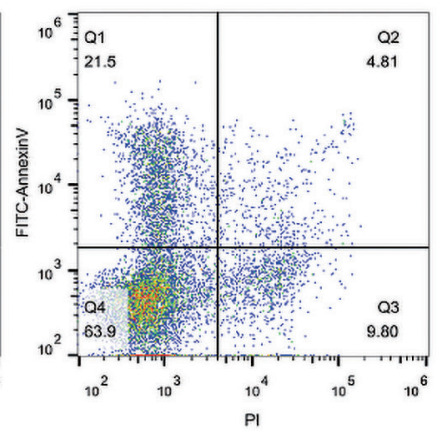

miR-124
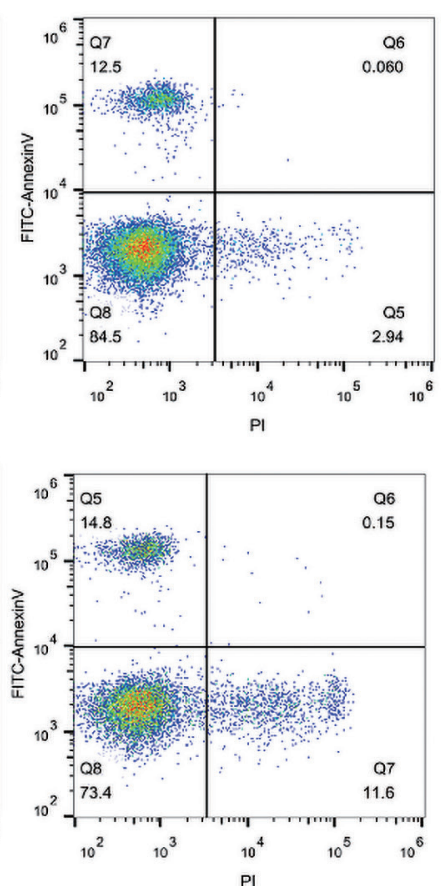

miR-NC $\square$ miR-NC + CAPN4

$\square$ miR-124 $\square$ miR-124+ CAPN4

Necroptosis (Annexin V-/PI+)

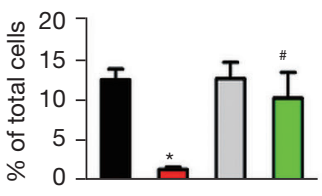

Apoptosis (Annexin V+/PI-)

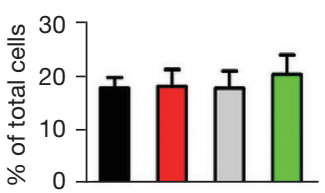

$\square$ miR-NC $\square$ miR-NC + CAPN4

$\square$ miR-124 $\square$ miR-124+ CAPN4

Necroptosis (Annexin V-/PI+)

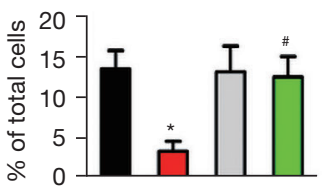

Apoptosis (Annexin V+/PI-)

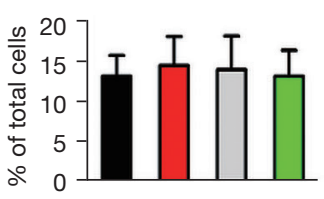

Figure 4 MiR-124 decreases cisplatin-induced necroptosis but not apoptosis by repressing calpain small subunit 1 (CAPN4). The function of miR-124 and/or on the level of apoptosis and necroptosis in cisplatin-treated Caki-1 (A) and 786-O (B) cells were evaluated by flow cytometric analysis. *, $\mathrm{P}<0.05$ vs. miR-NC group;, $\mathrm{P}<0.05$ vs. miR-124 group. 


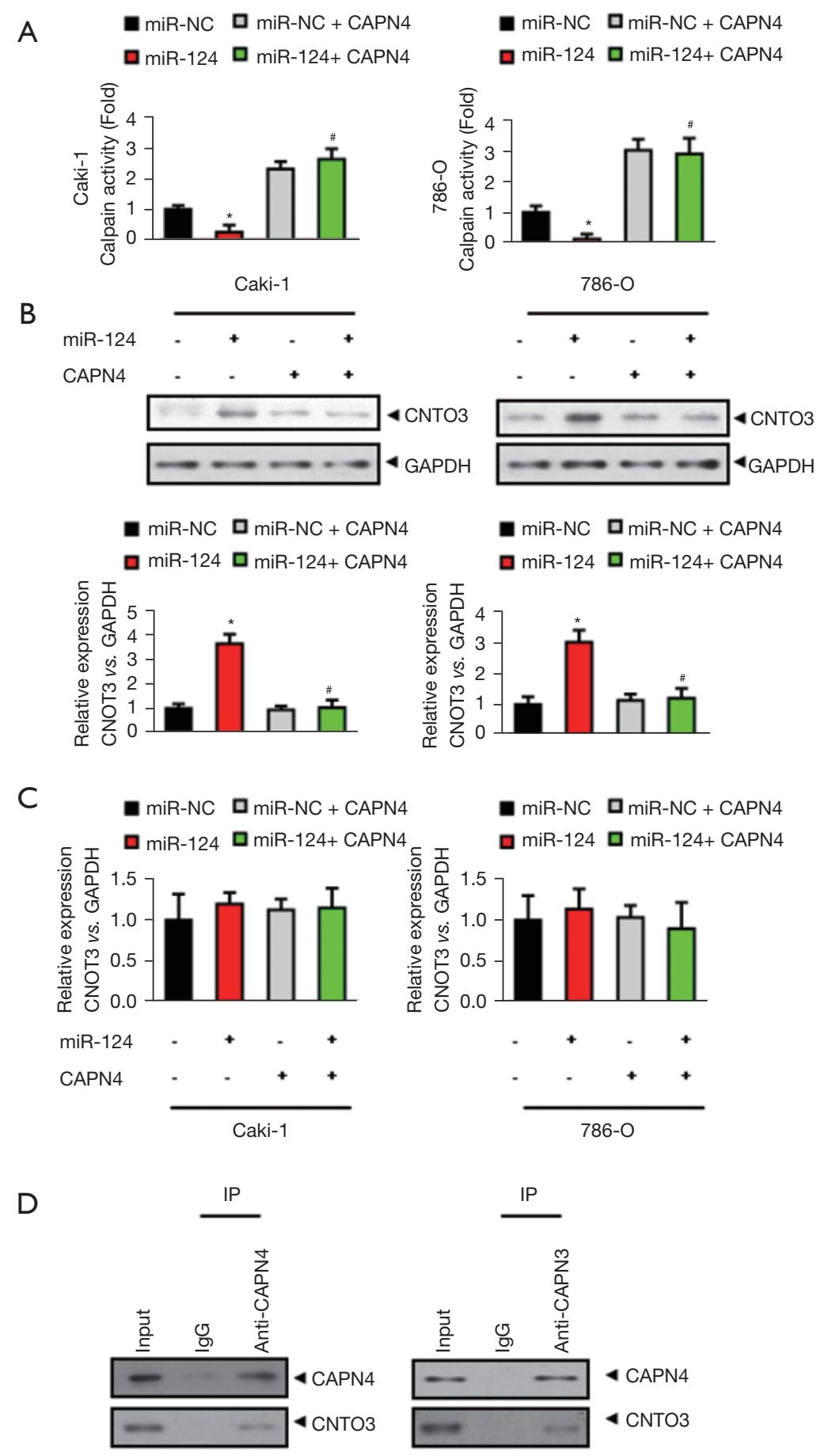

Figure 5 Calpain small subunit 1 (CAPN4) directly interacts with CCR4-NOT transcription complex subunit 3 (CNOT3) and promotes its degradation. (A) The calpain activity assay revealed that the decreased calpain activity in Caki-1 and 786-O cells were significantly increased after CAPN4 overexpression. (B) The protein levels of CNOT3 in miR-124-overexpressed Caki-1 and 786-O cells was analyzed by western blot analysis (C) The mRNA levels of CNOT3 in miR-124-overexpressed Caki-1 and 786-O cells was analyzed by real-time PCR(polymerase chain reaction) analysis. (D) Co-immunoprecipitation assays were performed in 786-O cells. Endogenous CAPN4 and CNOT3 were coimmunoprecipitated by anti-CAPN4 and anti CNOT3 antibodies. * $\mathrm{P}<0.05$ vs. miR-NC group; ${ }^{*}, \mathrm{P}<0.05$ vs. miR-124 group. 
A

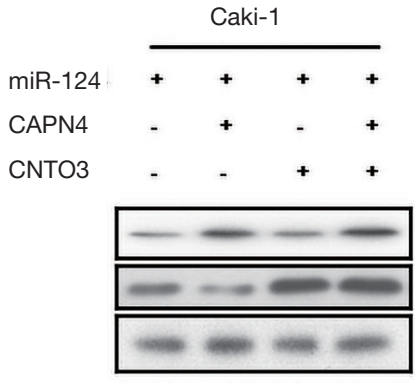

miR-124

a miR-124+ CAPN4
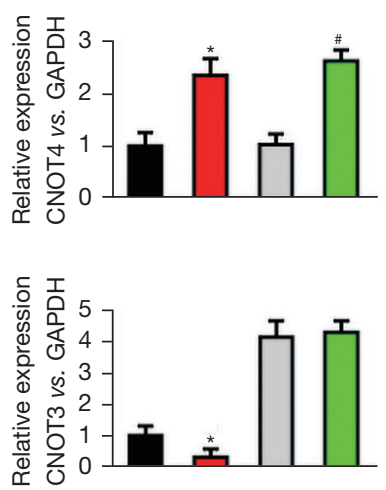

B

$$
\begin{aligned}
& \text { miR-124 } \\
& \text { miR-124+ CAPN4 }
\end{aligned}
$$

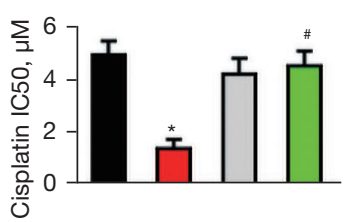

C

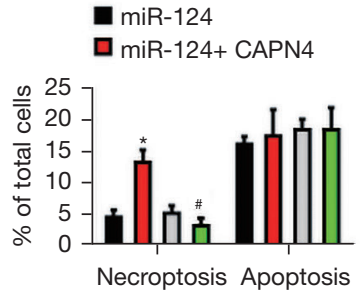

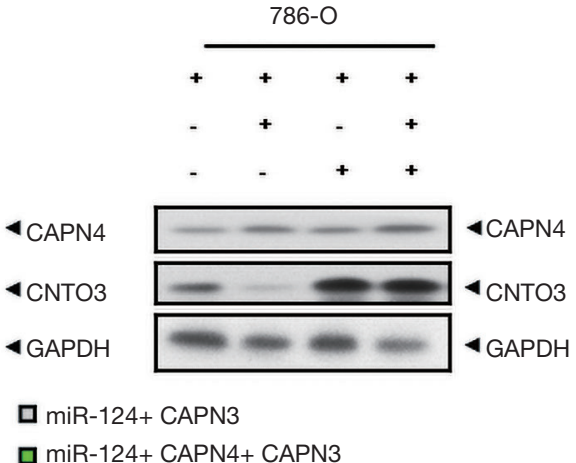

口 miR-124+ CAPN4+ CAPN3
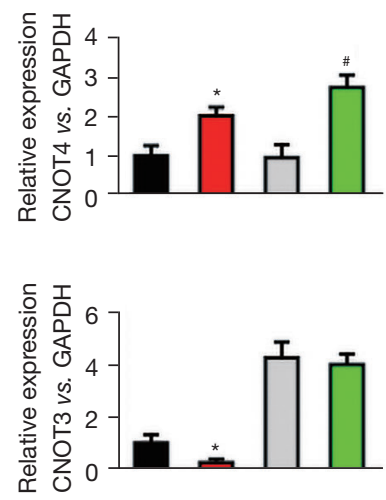

miR-124+ CAPN3

口 miR-124+ CAPN4+ CAPN3

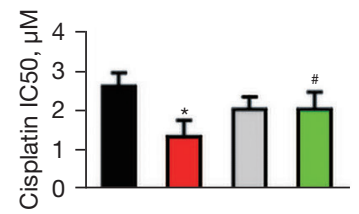

口 miR-124+ CAPN3

miR-124+ CAPN4+ CAPN3

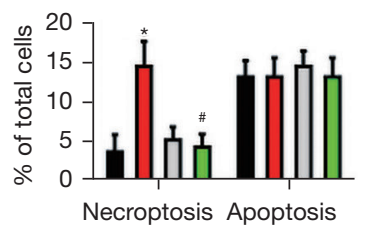

Figure 6 MiR-124 decreases cisplatin sensitivity and cisplatin-induced necroptosis by inhibiting calpain small subunit 1 (CAPN4)mediated CCR4-NOT transcription complex subunit 3 (CNOT3) degradation. (A) Western blot and quantitative real-time PCR (qPCR) analysis revealed that the protein and mRNA levels of CAPN4 and CNOT3 in different groups in Caki-1 and 786-O cells (miR-124, miR124+CAPN4, miR-124+CNOT3, miR-124+ CPAN4+ CNOT3). (B) The effect of CAPN4 and/or CNOT3 on cell viability and the IC50 (half maximal inhibitory concentration) value of miR-124-overexpressed Caki-1 and 786-O cells to cisplatin were evaluated using the Cell Counting Kit-8 (CCK-8) assay. (C) The effect of CAPN4 and/or CNOT3 on the level of necroptosis in miR-124-overexpressed Caki-1 and 786-O cells to cisplatin were evaluated by flow cytometric analysis. *, $\mathrm{P}<0.05$ vs. miR-124 group; ${ }^{*}, \mathrm{P}<0.05$ vs. miR-124+ CAPN4 group. 
A
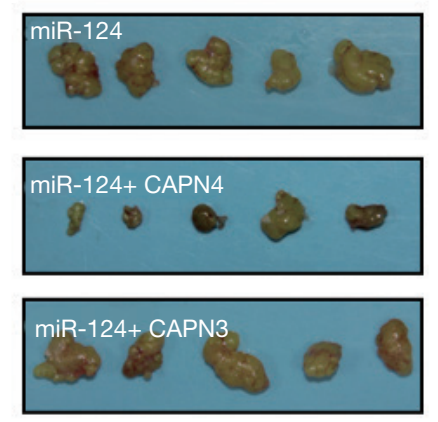

miR-124+CAPN4+ CAPN3 (4) $80 \mathrm{~g}$

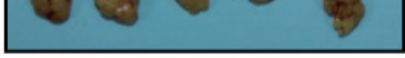

B
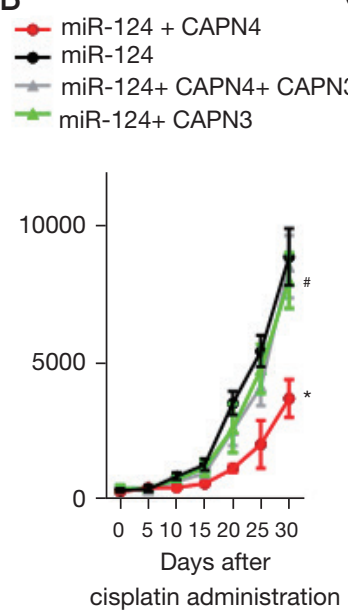

C

miR-124

amiR-124+ CAPN4

amiR-124+ CAPN3

口iR-124+ CAPN4+ CAPN3

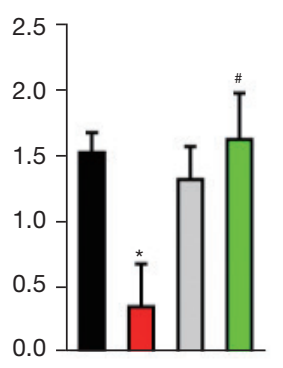

\section{D}

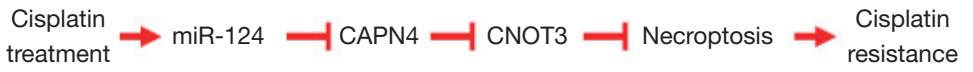

Figure 7 Effect of miR-124-calpain small subunit 1 (CANP4)-CCR4-NOT transcription complex subunit 3 (CNOT3) on the cisplatinresistance of 786-O cells in vivo. (A) Images of xenograft tumors formation from miR-124-overexpressed 786-O cells with or without CAPN4 and/or CNOT3. (B) The average volume of tumors is shown as mean \pm SEM (standard error of mean). (C) Tumors from indicated xenograft mice were weighed immediately after removal and the average tumor weight is indicated as mean \pm SEM. (D) A schematic model of cisplatin-induced miR-124 expression and its underlying mechanism in cisplatin resistance in $\mathrm{RCC}$. *, $\mathrm{P}<0.05$ vs. miR-124 group; ${ }^{\text {, }}$ $\mathrm{P}<0.05$ vs. miR-124+CAPN4 group.

cells after treatment with cisplatin (Figure 7A,7B). However, tumors derived from miR-124+CNOT3- or miR124+CAPN4+CNOT3-transfected 786-O cells were similar to those derived from only miR-124-transfected cells (Figure $7 A, 7 B)$. These data were further verified by endpoint analysis of explanted tumor weight (Figure $7 C$ ). Overall, the in vivo results demonstrate that miR-124 attenuates cisplatin sensitivity via inhibiting CAPN4mediated CNOT3 degradation (Figure 7D).

\section{Discussion}

Although bevacizumab/interferon- $\alpha$, everolimus and pazopanib are used as first-line agents in advanced RCC, chemotherapy is still widely used in other carcinomas. Cisplatin is one of the most effective chemotherapy drugs, the underlying mechanism of cisplatin resistance has been studied for decades; however, there are no effective pharmacological operations to overcome this form of complex resistance (29-31). It has been widely reported that miRNAs regulate cisplatin resistance in various cancers (31-35), but has rarely been reported in RCC. Recently,
miR-126 targeting SERPINE1 (36) and miR-148a targeting Rab14 (37) were identified to regulate cisplatin-resistance in RCC, and it was also reported that miR-124 represses FZD5 to attenuate P-glycoprotein-mediated doxorubicinand vinblastine-resistance in RCC (38). Therefore, the purpose of this study was to investigate the role of miR-124 in cisplatin resistance in RCC. We used high-throughput miRNA microarray analysis to assess the role of miRNAs in cisplatin resistance in RCC cells. Our data showed that miR-124 was dramatically increased after cisplatin treatment, and that overexpression of miR-124 decreased cisplatin sensitivity. Although numerous descriptive studies have shown that miR-124 inhibits cell proliferation in a variety of tumors, the present study identified the role of miR-124 in regulating cisplatin resistance for the first time. To understand the mechanism of miR-124 regulation of cisplatin resistance in RCC, we first found that miR-124 targets CAPN4's 3'-UTR to inhibit its expression. CAPN4 is the regulatory subunit of the catalytic subunits calpain 1 and calpain2 $(39,40)$. We previously reported that CAPN4 is a promising biomarker for metastatic RCC (41), which activates and promotes RCC cell proliferation via the focal 
adhesion kinase (FAK) signaling pathway (26). It has also been reported that CAPN4 is a target of miR-99a and miR-491, and is involved in cisplatin resistance in gastric cancer (42). However, the mechanism of CAPN4 regulating RCC cisplatin-resistance is unknown.

In the current investigation, we discovered a new mechanism: miR-124 decreases the cisplatin sensitivity via inhibition of CAPN4. Furthermore, this study demonstrated that CAPN4 may directly interact with CNOT3 and affect its degradation, but not inhibit its expression. CNOT3 is an integral part of the CCR4 -NOT transcription complex and plays a general transcriptional regulatory role (43). It has been reported that CNOT3 acts as a new biomarker for molecular and prognostic classification of early-stage colon cancer (44). Moreover, CNOT3 targets specific mRNAs to prevent cell necrosis (45). Hence, the connection between necroptosis in cisplatin-resistant cells and miR-124-CAPN4-CNOT3-aixs excited our curiosity. Intriguingly, we identified that cisplatin-elevated miR-124 decreases RCC cells' necroptosis by preserving CNOT3 from CAPN4 mediated-degradation. Necroptosis, a form cell death regulation independent of apoptotic mechanisms (46), has not received sufficient attention, and may become a novel effective method to eliminate tumor cells $(47,48)$. Thus, its activation may be a promising option for inducing death of drug-resistant cancer cells.

Given that necrosis induces cell death by bypassing apoptosis retardation, efforts are being made to develop necrotic induction compounds for the treatment of drugresistant cancers (49-52). Two attractive drug resistance strategies are currently being studied that directly address the causes of apoptosis blocking or alternative mechanisms of cell death, including induced necrosis (53). In this study, we discovered that miR-124 decreases cisplatin sensitivity via inhibition of cisplatin-induced necroptosis.

In conclusion, this study showed that miRNA-124 regulates the sensitivity of renal cancer cells to cisplatininduced necroptosis by inhibiting CAPN4-mediated CNOT3 degradation. Understanding the regulation of cisplatin-resistant necrosis by miR-124 may be useful in investigating new targets for the treatment of RCC, and the miR-124-CAPN4-CNOT3 signaling axis may be a potential alternative therapeutic strategy for overcoming cisplatin-resistant in RCC.

\section{Acknowledgments}

Funding: None.

\section{Footnote}

Reporting Checklist: The authors have completed the ARRIVE reporting checklist. Available at https://dx.doi. org/10.21037/tau-21-777

Data Sharing Statement: Available at https://dx.doi. org/10.21037/tau-21-777

Conflicts of Interest: All authors have completed the ICMJE uniform disclosure form (available at https://dx.doi. org/10.21037/tau-21-777). The authors have no conflicts of interest to declare.

Etbical Statement: The authors are accountable for all aspects of the work in ensuring that questions related to the accuracy or integrity of any part of the work are appropriately investigated and resolved. This study was approved by the Ethics Committee of the Third Affiliated Hospital of Soochow University. The operation process of all experimental animals was strictly in accordance with the "Guide to the Care and Use of Experimental Animals" [2016].

Open Access Statement: This is an Open Access article distributed in accordance with the Creative Commons Attribution-NonCommercial-NoDerivs 4.0 International License (CC BY-NC-ND 4.0), which permits the noncommercial replication and distribution of the article with the strict proviso that no changes or edits are made and the original work is properly cited (including links to both the formal publication through the relevant DOI and the license). See: https://creativecommons.org/licenses/by-nc-nd/4.0/.

\section{References}

1. Cairns P. Renal cell carcinoma. Cancer Biomark 2010;9:461-73.

2. Mollica V, Di Nunno V, Massari F. Pembrolizumab plus axitinib: a new treatment option for patients with metastatic renal cell carcinoma. Chin Clin Oncol 2019;8:S21.

3. Adelaiye-Ogala R, Budka J, Damayanti NP, et al. EZH2 Modifies Sunitinib Resistance in Renal Cell Carcinoma by Kinome Reprogramming. Cancer Res 2017;77:6651-66.

4. Wang X, Cheng Y, Zhu Y, et al. Epigenetic silencing of ASPP1 confers 5-FU resistance in clear cell renal cell carcinoma by preventing p 53 activation. Int J Cancer 2017;141:1422-33. 
5. Robinson SP, Boult JKR, Vasudev NS, et al. Monitoring the Vascular Response and Resistance to Sunitinib in Renal Cell Carcinoma In Vivo with Susceptibility Contrast MRI. Cancer Res 2017;77:4127-34.

6. Naito S, Makhov P, Astsaturov I, et al. LDL cholesterol counteracts the antitumour effect of tyrosine kinase inhibitors against renal cell carcinoma. Br J Cancer 2017;116:1203-7.

7. Lewis BP, Burge CB, Bartel DP. Conserved seed pairing, often flanked by adenosines, indicates that thousands of human genes are microRNA targets. Cell 2005;120:15-20.

8. Wu F, Zhi X, Xu R, et al. Exploration of microRNA profiles in human colostrum. Ann Transl Med 2020;8:1170.

9. Fan $\mathrm{Y}, \mathrm{Ma} \mathrm{X}, \mathrm{Li} \mathrm{H}$, et al. miR-122 promotes metastasis of clear-cell renal cell carcinoma by downregulating Dicer. Int J Cancer 2018;142:547-60.

10. Li Y, Zhang D, Wang J. MicroRNA-373 promotes tumorigenesis of renal cell carcinoma in vitro and in vivo. Mol Med Rep 2017;16:7048-55.

11. Zhai W, Sun Y, Guo C, et al. LncRNA-SARCC suppresses renal cell carcinoma (RCC) progression via altering the androgen receptor(AR)/miRNA-143-3p signals. Cell Death Differ 2017;24:1502-17.

12. Chen X, Wang X, Ruan A, et al. miR-141 is a key regulator of renal cell carcinoma proliferation and metastasis by controlling EphA2 expression. Clin Cancer Res 2014;20:2617-30.

13. Wang X, Chen X, Han W, et al. miR-200c Targets CDK2 and Suppresses Tumorigenesis in Renal Cell Carcinoma. Mol Cancer Res 2015;13:1567-77.

14. Liu W, Zabirnyk O, Wang H, et al. miR-23b targets proline oxidase, a novel tumor suppressor protein in renal cancer. Oncogene 2010;29:4914-24.

15. $\mathrm{Mu} \mathrm{W}, \mathrm{Hu} \mathrm{C}$, Zhang $\mathrm{H}$, et al. miR-27b synergizes with anticancer drugs via p53 activation and CYP1B1 suppression. Cell Res 2015;25:477-95.

16. Yamada Y, Hidaka H, Seki N, et al. Tumor-suppressive microRNA-135a inhibits cancer cell proliferation by targeting the c-MYC oncogene in renal cell carcinoma. Cancer Sci 2013;104:304-12.

17. Khella HWZ, Butz H, Ding Q, et al. miR-221/222 Are Involved in Response to Sunitinib Treatment in Metastatic Renal Cell Carcinoma. Mol Ther 2015;23:1748-58.

18. Xiao HJ, Ji Q, Yang L, et al. In vivo and in vitro effects of microRNA-124 on human gastric cancer by targeting JAG1 through the Notch signaling pathway. J Cell Biochem 2018;119:2520-34.

19. Shi B, Wang Y, Yin F. MALAT1/miR-124/Capn4 axis regulates proliferation, invasion and EMT in nasopharyngeal carcinoma cells. Cancer Biol Ther 2017;18:792-800.

20. Li SL, Gao HL, Lv XK, et al. MicroRNA-124 inhibits cell invasion and epithelial-mesenchymal transition by directly repressing Snail2 in gastric cancer. Eur Rev Med Pharmacol Sci 2017;21:3389-96.

21. Cui M, Wang J, Li Q, et al. Long non-coding RNA HOXA11-AS functions as a competing endogenous RNA to regulate ROCK1 expression by sponging miR-124-3p in osteosarcoma. Biomed Pharmacother 2017;92:437-44.

22. Liu K, Yao H, Lei S, et al. The miR-124-p63 feedback loop modulates colorectal cancer growth. Oncotarget 2017;8:29101-15.

23. Butz H, Szabó PM, Khella HW, et al. miRNA-target network reveals miR-124as a key miRNA contributing to clear cell renal cell carcinoma aggressive behaviour by targeting CAV1 and FLOT1. Oncotarget 2015;6:12543-57.

24. Gebauer K, Peters I, Dubrowinskaja N, et al. Hsamir-124-3 CpG island methylation is associated with advanced tumours and disease recurrence of patients with clear cell renal cell carcinoma. Br J Cancer 2013;108:131-8.

25. Shi Z, Chen Q, Li C, et al. MiR-124 governs glioma growth and angiogenesis and enhances chemosensitivity by targeting R-Ras and N-Ras. Neuro Oncol 2014;16:1341-53.

26. Shen J, Zhuang Q, Chen Z, et al. Capn4 induces human renal cancer cell proliferation by activating $\mathrm{NF}-\kappa \mathrm{B}$ signaling pathway through FAK phosphorylation. Int J Clin Exp Pathol 2017;10:7466-74.

27. Shimada M, Greer PA, McMahon AP, et al. In vivo targeted deletion of calpain small subunit, Capn4, in cells of the osteoblast lineage impairs cell proliferation, differentiation, and bone formation. J Biol Chem 2008;283:21002-10.

28. Zheng X, Dumitru R, Lackford BL, et al. Cnot1, Cnot2, and Cnot 3 maintain mouse and human ESC identity and inhibit extraembryonic differentiation. Stem Cells 2012;30:910-22.

29. Liu D, Luo M, Hu J, et al. Osteopontin enhances cisplatin resistance of human A549 lung cancer cells via stimulating the PI3K signaling pathway and upregulating ERCC1 expression. Transl Cancer Res 2020;9:3258-65.

30. Endo S, Xia S, Suyama M, et al. Synthesis of Potent and Selective Inhibitors of Aldo-Keto Reductase 1B10 and Their Efficacy against Proliferation, Metastasis, and Cisplatin Resistance of Lung Cancer Cells. J Med Chem 2017;60:8441-55.

31. Li B, Wang W, Li Z, et al. MicroRNA-148a-3p 
enhances cisplatin cytotoxicity in gastric cancer through mitochondrial fission induction and cyto-protective autophagy suppression. Cancer Lett 2017;410:212-27.

32. Cheng MW, Shen ZT, Hu GY, et al. Prognostic Significance of microRNA-7 and its Roles in the Regulation of Cisplatin Resistance in Lung Adenocarcinoma. Cell Physiol Biochem 2017;42:660-72.

33. Li X, Jin $Y, M u ~ Z$, et al. MicroRNA-146a-5p enhances cisplatin-induced apoptosis in ovarian cancer cells by targeting multiple anti-apoptotic genes. Int J Oncol 2017;51:327-35.

34. Tian J, Xu YY, Li L, et al. MiR-490-3p sensitizes ovarian cancer cells to cisplatin by directly targeting ABCC2. Am J Transl Res 2017;9:1127-38.

35. Zeng SG, Xie JH, Zeng QY, et al. MicroRNA-497$5 \mathrm{p}$ negatively regulates the proliferation and cisplatin resistance of non-small cell lung cancer cells by targeting YAP1 and TEAD1. Transl Cancer Res 2019;8:2470-80.

36. Liu $\mathrm{W}$, Chen $\mathrm{H}$, Wong $\mathrm{N}$, et al. Pseudohypoxia induced by miR-126 deactivation promotes migration and therapeutic resistance in renal cell carcinoma. Cancer Lett 2017;394:65-75.

37. Kim EA, Kim TG, Sung EG, et al. miR-148a increases the sensitivity to cisplatin by targeting Rab14 in renal cancer cells. Int J Oncol 2017;50:984-92.

38. Long QZ, Du YF, Liu XG, et al. miR-124 represses FZD5 to attenuate $\mathrm{P}$-glycoprotein-mediated chemo-resistance in renal cell carcinoma. Tumour Biol 2015;36:7017-26.

39. Dai Z, Zhou SL, Zhou ZJ, et al. Capn 4 contributes to tumour growth and metastasis of hepatocellular carcinoma by activation of the FAK-Src signalling pathways. J Pathol 2014;234:316-28.

40. Arthur JS, Greer PA, Elce JS. Structure of the mouse calpain small subunit gene. Biochim Biophys Acta 1998;1388:247-52.

41. Zhuang Q, Qian X, Cao Y, et al. Capn4 mRNA level is correlated with tumour progression and clinical outcome in clear cell renal cell carcinoma. J Int Med Res 2014;42:282-91.

42. Zhang Y, Xu W, Ni P, et al. MiR-99a and MiR-491 Regulate Cisplatin Resistance in Human Gastric Cancer Cells by Targeting CAPNS1. Int J Biol Sci 2016;12:1437-47.

43. Watanabe C, Morita M, Hayata T, et al. Stability of mRNA influences osteoporotic bone mass via CNOT3. Proc Natl Acad Sci U S A 2014;111:2692-7.

44. Cejas P, Cavazza A, Yandava CN, et al. Transcriptional
Regulator CNOT3 Defines an Aggressive Colorectal Cancer Subtype. Cancer Res 2017;77:766-79.

45. Suzuki T, Kikuguchi C, Sharma S, et al. CNOT3 suppression promotes necroptosis by stabilizing mRNAs for cell death-inducing proteins. Sci Rep 2015;5:14779.

46. Rosentreter D, Funken D, Reifart J, et al. RIP1Dependent Programmed Necrosis is Negatively Regulated by Caspases During Hepatic Ischemia-Reperfusion. Shock 2015;44:72-6.

47. Yang C, Li J, Yu L, et al. Regulation of RIP3 by the transcription factor $\mathrm{Sp} 1$ and the epigenetic regulator UHRF1 modulates cancer cell necroptosis. Cell Death Dis 2017;8:e3084.

48. Cekay MJ, Roesler S, Frank T, et al. Smac mimetics and type II interferon synergistically induce necroptosis in various cancer cell lines. Cancer Lett 2017;410:228-37.

49. Steinhart L, Belz K, Fulda S. Smac mimetic and demethylating agents synergistically trigger cell death in acute myeloid leukemia cells and overcome apoptosis resistance by inducing necroptosis. Cell Death Dis 2013;4:e802.

50. Laukens B, Jennewein C, Schenk B, et al. Smac mimetic bypasses apoptosis resistance in FADD- or caspase8-deficient cells by priming for tumor necrosis factor a-induced necroptosis. Neoplasia 2011;13:971-9.

51. Bonapace L, Bornhauser BC, Schmitz M, et al. Induction of autophagy-dependent necroptosis is required for childhood acute lymphoblastic leukemia cells to overcome glucocorticoid resistance. J Clin Invest 2010;120:1310-23.

52. Gerges S, Rohde K, Fulda S. Cotreatment with Smac mimetics and demethylating agents induces both apoptotic and necroptotic cell death pathways in acute lymphoblastic leukemia cells. Cancer Lett 2016;375:127-32.

53. Xu B, Xu M, Tian Y, et al. Matrine induces RIP3dependent necroptosis in cholangiocarcinoma cells. Cell Death Discov 2017;3:16096.

(English Language Editor: A. Kassem)

Cite this article as: Mao Q, Zhuang Q, Shen J, Chen Z, Xue D, Ding T, He X. MiRNA-124 regulates the sensitivity of renal cancer cells to cisplatin-induced necroptosis by targeting the CAPN4-CNOT3 axis. Transl Androl Urol 2021;10(9):36693683. doi: 10.21037/tau-21-777 